УДК 616.12-008.331.1-053.7-085-037:575.1

DOI: $10.26435 /$ UC.V0I1(38).697

\author{
Е.Г. Ляшенко, И.В. Мухин
}

ГОО ВПО «Донецкий национальный медицинский университет имени М. Горького», Донецк

\title{
ДИНАМИКА АКТИВНОСТИ СИСТЕМНОГО ВОСПАЛИТЕЛЬНОГО ОТВЕТА ПОД ВЛИЯНИЕМ ЛЕЧЕНИЯ У ГОРНОРАБОЧИХ УГОЛЬНЫХ ШАХТ ДОНБАССА, СТРАДАЮЩИХ ПЫЛЕВОЙ ХОБЛ С ДИСЛИПИДЕМИЕЙ
}

Доминирующей концепцией прогрессирования хронической обструктивной болезни легких (ХОБЛ) не зависимо от ее происхождения является самоподдержание хронического воспаления [7]. В этом контексте рассматривается две параллельно существующие гипотезы. Согласно одной из них, хроническое неспецифическое респираторное воспаление ведет к формированию основных морфологических и функциональных проявлений ХОБЛ. Вторая базируется на возникновении и самоподдержании аутоимунных реакций, направленных против структур респираторного аппарата [5].

Пылевая ХОБЛ у горнорабочих угольных шахт Донбасса занимает около 10-19\% всех случаев ХОБЛ [8]. Для ее развития важное значение имеют стаж работы и концентрация поллютантов в воздухе рабочей зоны (т.е. суммарная нагрузка), химический состав, физические, биологические свойства промаэрозоля, длительность импрегнации пыли, возраст работника, курение [6]. Присутствие одновременно промышленного аэрозоля и других неблагоприятных факторов производственной среды увеличивает вероятность развития профессиональной ХОБЛ. Физические перегрузки или высокая температура окружающей среды существенно увеличивают минутный объем дыхания и поступление патогенных частиц в бронхи и легкие [7].

Цель работы заключалась в анализе влияния трех режимов терапии на показатели активности системного воспалительного ответа у горнорабочих угольных шахт Донбасса, страдающих пылевой ХОБЛ.

\section{МАТЕРИАЛ И МЕТОДЫ}

В исследование включены 148 больных ХОБЛ пылевой этиологии, которые находились на лечении в Республиканском центре профпатологии и реабилитации МЗ ДНР с 2006 по 2017 год.

Верификация ХОБЛ и оценка степени тяжести проводилась в соответствии с критери- ями GOLD. Наличие ХОБЛ было подтверждено анамнестически и инструментально (объем форсированного выдоха за 1-ю секунду (ОФВ1)/ функциональная жизненная емкость легких (ФЖЕЛ)<70\%, прирост ОФВ1<12\% и < 200 мЛ при проведении пробы с короткодействующим бета-2 агонистом.

Критериями включения были: мужчины в возрасте от 35 до 60 лет; стаж работы в подземных условиях 10 и более лет; согласие участвовать в клиническом исследовании; установленный диагноз ХОБЛ согласно рекомендациям GOLD (2017); пациенты 2-ой и 3-ей стадий заболевания в фазе обострения; присутствие 2 и более признаков обострения ХОБЛ (усиление одышки, повышение продукции мокроты или ее гнойности); наличие сопутствующей дислипидемии.

Критерии исключения: наличие в анамнезе/статусе бронхиальной астмы, бронхоэктатической болезни, туберкулеза легких, онкологических заболеваний, тромбоэмболии ветвей легочной артерии, эпилептиформных судорожных приступов, клаустрофобии; аллергический ринит; признаки декомпенсации легочного сердца; пациенты, не способные правильно выполнять дыхательный маневр при тестировании функции внешнего дыхания; почечная недостаточность, тяжелая патология печени, артериальная гипертензия, неконтролируемая терапией, сердечная недостаточность III-IV функционального класса; лечение ингаляционными или системными кортикостероидами в течение 2-х предшествующих месяцев.

Пациенты, включенные в исследование, методом случайной выборки были распределены в 3 группы наблюдения, статистически гомогенные по полу $(\chi 2=0,28, \mathrm{p}=0,70)$, возрасту $(\mathrm{t}=0,39$, $\mathrm{p}=0,88)$, длительности и тяжести заболевания

( Е.Г. Ляшенко, И.В. Мухин, 2021

(c) Университетская Клиника, 2021 
$(\mathrm{t}=0,91, \mathrm{p}=0,16$ и $\chi 2=0,47, \mathrm{p}=0,52$ соотвественно). 1 -я $(\mathrm{n}=25)$ включала пациентов, которые кроме базисного лечения получали сеансы гипербарической оксигенации (ГБО), 2-я (n=32) - беклометазон дипропионат в дозе 800 мкг/сутки, в 3-ю (n=33) группу вошли пациенты, получавшие только базисную терапию, которая предусматривала использование бронхолитика тиотропия бромида, антибиотиков (при наличии признаков бронхиальной инфекции). При необходимости пациенты использовали сальбутамол в режиме «по требованию».

Исследование сывороточных концентраций цитокинов - интерлейкина 1Р и интерлейкина 8 (ИЛ-1Р и ИЛ-8) проводили с использованием реагентов фирмы «Вектор-Бест» (Россия) на анализаторе RT-2100C (Китай).

Концентрацию фактора некроза опухоли (ФНО- $\alpha)$ определяли при помощи реагентов «ИФА-TNF-alpha» производства «Цитокин» (Россия), гранулоцит-колонийстимулирующего фактора при помощи набора реактивов «ИФАG-CSF» производства OOO «Цитокин» (Россия) на анализаторе «Униплан» АИФР-01.

Сеансы ГБО проводились в одноместных барокамерах БЛКС-303МК. Курс включал 10 сеансов, величина избыточного давления 0,2-0,5 атм., экспозиция изопрессии 30-40 мин.
Оценка клинических симптомов и переносимости терапии больными ХОБЛ в фазе обострения проводилась при поступлении в стационар, через 7 и 14 дней от ее начала.

Параметры, полученные у больных ХОБЛ сравнивали с аналогичными у 30 практически здоровых людей аналогичного пола и возраста.

Статистическая обработка результатов была проведена при помощи пакета прикладных программ Statistica for Windows, Release 6.5 StatSoft, Inc. Нормальность распределения оценивали в тесте Колмогоров-Смирнова. Цифровые данные представлены как средние значения и их ошибки $(\mathrm{M} \pm \mathrm{m})$. Достоверность различий одноименных количественных показателей оценивалось при помощи парного $\mathrm{t}$ - критерия. Для оценивания различий качественных показателей использовали критерий $\chi 2$. Различия считались статистически достоверными при уровне значимости р $<0,05$.

\section{РЕЗУЛЬТАТЫ И ОБСУЖДЕНИЕ}

Обострение ХОБЛ при исходном исследовании характеризовалось повышением уровня провоспалительных цитокинов во всех группах больных без наличия достоверных различий между группами (см. табл.).

Динамика содержания уровня провоспалительных цитокинов в процессе курсового лечения (Mะm)

\begin{tabular}{|c|c|c|c|c|}
\hline \multirow{2}{*}{ Цитокины } & \multirow{2}{*}{ Здоровые $(\mathrm{n}=30)$} & \multicolumn{3}{|c|}{ Группы больных } \\
\hline & & $1-я(n=25)$ & $2-я(n=32)$ & 3-я $(\mathrm{n}=33)$ \\
\hline \multicolumn{5}{|l|}{ ИЛ-1Р, пкг/мЛ } \\
\hline исходно & \multirow{3}{*}{$8,65 \pm 1,52$} & $199,45 \pm 5,31^{*}$ & $201,34 \pm 5,27^{*}$ & $203,85 \pm 5,48^{*}$ \\
\hline через 7 дней & & $105,61 \pm 5,14^{*} \&$ & $116,74 \pm 5,38^{*} \&$ & $121,48 \pm 5,75^{* \Delta \triangleleft \&}$ \\
\hline через 14 дней & & $41,23 \pm 4,82^{*} \S$ & $49,43 \pm 4,73^{* \# \S}$ & $57,80 \pm 4,92^{*} \Delta \triangleleft \S$ \\
\hline \multicolumn{5}{|l|}{ ФНО- $\alpha$, пкг/мл } \\
\hline исходно & \multirow{3}{*}{$7,12 \pm 1,13$} & $178,23 \pm 6,34^{*}$ & $181,52 \pm 6,41^{*}$ & $173,84 \pm 6,58^{*}$ \\
\hline через 7 дней & & $106,43 \pm 5,88^{*} \&$ & $109,38 \pm 5,61^{* \&}$ & $119,71 \pm 5,93^{* \Delta \Delta \&}$ \\
\hline через 14 дней & & $39,44 \pm 5,24^{*} \S$ & $45,27 \pm 5,25^{* \# \S}$ & $49,37 \pm 5,81^{*} \Delta \S$ \\
\hline \multicolumn{5}{|l|}{ ИЛ-8, пкг/мл } \\
\hline исходно & \multirow{3}{*}{$13,41 \pm 1,49$} & $161,12 \pm 5,78^{*}$ & $163,24 \pm 5,83^{*}$ & $169,21 \pm 5,94^{*}$ \\
\hline через 7 дней & & $99,74 \pm 5,25 * \&$ & $103,81 \pm 5,74^{* * \&}$ & $119,38 \pm 5,72^{* \Delta \Delta \&}$ \\
\hline через 14 дней & & $65,74 \pm 5,27^{* \S}$ & $69,83 \pm 5,46^{* \# \S}$ & $74,32 \pm 5,62^{* \Delta \triangleleft \S}$ \\
\hline
\end{tabular}

Примечание: * - различия между аналогичными показателями у больных и здоровых статистически достоверны; \# - различия между аналогичными показателями у больных 1 -ой и 2-ой групп статистически достоверны; $\Delta$ - различия между аналогичными показателями у больных 1-ой и 3-ей групп статистически достоверны; $\diamond-$ различия между аналогичными показателями у больных 2-ой и 3-ей групп статистически достоверны \& - различия между исходными показателями и через 7 дней статистически достоверны; § - различия между исходными показателями и через 7 дней статистически достоверны. 
Терапия противовоспалительными средствами оказывала положительное влияние на интенсивность регрессирования уровня провоспалительных цитокинов [10], однако полученные результаты в группах были различными. Так, у больных, получавших в комплексном лечении обострения заболевания ГБО, уровень ИЛ-1Р к 7 дню лечения снизился с 199,45 $\pm 5,31$ до 105,61士5,14 пкг/мл (на 47,0\%, p<0,001), а к 14 дню - в 4,8 раза и составил в целом по группе $41,23 \pm 4,82$ пкг/мл ( $<<0,001)$. Несмотря на значительное и достоверное снижение ИЛ-1Р к окончанию курсового лечения содержание его в крови оставалось достоверно повышенным по сравнению с таковым в группе контроля. Одновременно с этим было отмечено, что на фоне лечения ГБО уменьшалась активация ФНО- $\alpha$ на 7 сутки с 178,23 $\pm 6,34$ до 106,43 $\pm 5,88$ пкг/мл (на $40,3 \%, \mathrm{p}<0,001)$ и до $39,44 \pm 5,24$ пкг/мл на 14 сутки лечения, оставаясь повышенной почти в 5,4 раза по сравнению с группой контроля. К окончанию курсового лечения ГБО содержание в крови ИЛ-8 снизилось с $161,12 \pm 5,78$ до $65,74 \pm 5,27$ пкг/мл или в 2,5 раза ( $<<0,001)$ по сравнению с исходными данными.

Включение в комплексную терапию беклометазон дипропионата при обострении заболевания способствовало снижению всех провоспалительных цитокинов, однако их депрессия была менее выражена по сравнению с больными 1-ой группы. Так, ИЛ-1Р к 7 дню лечения

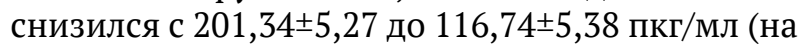
42,0\%, p<0,001), к 14 дню - в 4,1 раза и соста-

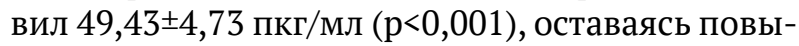
шенным по сравнению с контрольной группой в 5,7 раза ( $\mathrm{p}<0,001)$. После проведенной терапии беклометазоном дипропионатом к 7-у и 14-у дням лечения произошло высоко достоверное ( $<<0,001)$ снижение уровня экспрессии ФНО- $\alpha$ на $39,7 \%$ и $75,1 \%$ соответственно. Несмотря на значительное снижение активности ФНО- $\alpha$, содержание этого цитокина в крови оставалось достоверно повышенным в 6,4 раза по сравнению с группой контроля.

У больных 3-ей группы, получавших только базисное лечение отмечено снижение активации всех провоспалительных цитокинов: уровень ИЛ-1Р к 7-у дню лечения снизился с $203,85 \pm 5,48$ до $121,48 \pm 5,75$ пкг/мл (на $40,4 \%$, $\mathrm{p}<0,001)$, к 14-у дню в 3,5 раза и составил в целом по группе 57,8 44,92 пкг/мл (p<0,001). Одновременно с этим было отмечено, что на фоне базисной терапии уменьшалась активность ФНО- $\alpha$ на

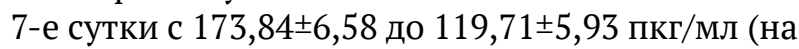

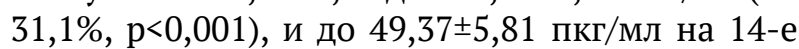
сутки лечения, оставаясь повышенной в 6,9 раза по сравнению с группой контроля. По завер- шению курсового лечения содержание в крови

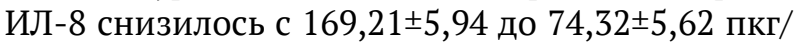
мл или в 2,3 раза ( $\mathrm{p}<0,001)$ по сравнению с исходными данными.

Частое развитие обострений у больных ХОБЛ приводит к ускорению прогрессирования бронхолегочного патологического процесса и вторичному вовлечению в процесс других висцеральных органов. В качестве одного из механизмов вовлечения внутренних органов рассматривается полиорганные аутоиммунные реакции с формированием антител, направленных против не только структур респираторного аппарата, но и оболочек сердца, щитовидной железы, суставов, эндокринных органов [9]. Рассмотрение данной проблемы с такой позиции позволяет лучше понять происхождение не только полиорганной, но и ухудшение течения (утяжеление) сочетанной (полиморбидной) патологии у больных ХОБЛ. Именно поэтому, превентирование обострений является одной из важнейших задач ведения больных ХОЗЛ. В этой связи, подавление и реактивация воспаления является одним из главных патогенетических направлений лечения такой категории больных. Вместе с тем, если снижение активности системной воспалительной неспецифической реакции во многом осуществимо благодаря современным методам антиинфламаторного лечения, то влияние терапии на аутоиммунный компонент воспаления во многом остается мало изученным [4].

Присутствие дислипидемии является одним из важных патогенетических механизмов, позволяющим с одной стороны активировать неспецифическое воспаление, а, с иной, участвовать в инициации атеросклеротического поражения жизненно важных органов, в первую очередь миокарда и, тем, самым, вносить дополнительную лепту в процессы формирования сердечной недостаточности и ишемической болезни сердца, как важнейших экстрапульмональных факторов прогрессирования ХОБЛ.

Несколько иначе обстоит дело с ХОБЛ производственной этиологии. При профессиональной ХОБЛ частички пыли могут рассматриваться в качестве триггера возникновения и поддержания воспаления [3]. Длительное, в течение десяти и более лет, воздействие газов, паров, пыли, дымов на эпителий дыхательных путей приводит первоначально к перегрузке мукоцилиарного аппарата, замедлению/остановке мукоцилиарного транспорта с нарушением респираторного клиренса. Это облегчает/ускоряет поступление агрессивных компонентов пыли в дистальные отделы респираторного тракта, где они в последующем повреждают эпителиальные клетки, альвеолоциты, инициируя хроническое 
интерстициальное воспаление. Другой путь активации/самоподдержания воспалительной реакции в этом случае заключается в непосредственном захвате частиц пыли или жидкостного аэрозоля макрофагами [2]. Невозможность эрадикации пыли, попавшей в легких, приводит с одной стороны к возникновению механизмов системной защиты (например, развитие пневмосклероза склероза), а, с другой, к возникновению и самоподдержанию аутоимунных реакций, результатом которых является диффузный склеротический процесс и постепенная утрата дыхательной поверхности $[1,4]$.

\section{В Ы В ОД Ы}

1. У горнорабочих угольных шахт с пылевой ХОБЛ и дислипидемией развивается гиперактивация глобального воспалительного ответа, причем, последний является одним из факторов, инициирующих появление и прогрессирование атеросклероза.

2. ГБО как компонент комплексной краткосрочной лечебно-реабилитационной программы позволяет достоверно снизить активность системного воспаления даже более эффективно, чем ингаляционная терапия глюкокортикоидными гормонами.

\section{Е.Г. Ляшенко, И.В. Мухин}

ГОО ВПО «Донецкий национальный медицинский университет имени М. Горького», Донецк

\section{ДИНАМИКА АКТИВНОСТИ СИСТЕМНОГО ВОСПАЛИТЕЛЬНОГО ОТВЕТА ПОД ВЛИЯНИЕМ ЛЕЧЕНИЯ У ГОРНОРАБОЧИХ УГОЛЬНЫХ ШАХТ ДОНБАССА, СТРАДАЮЩИХ ПЫЛЕВОЙ ХОБЛ С ДИСЛИПИДЕМИЕЙ}

Цель исследования заключалась в анализе влияния трех режимов терапии на показатели активности системного воспалительного ответа у больных хронической обструктивной болезнью легких пылевой этиологии с дислипидемией. У больных установлена гиперактивность системного воспалительного ответа. Гипербарическая оксигенация как компонент комплексной краткосрочной лечебно-реабилитационной программы позволяет достоверно уменьшить активность системного воспаления более эффективно, чем ингаляционная терапия бета-2 агонистами и глюкокортикоидными гормонами.

Ключевые слова: активность системного воспалительного ответа, хроническая обструктивная болезнь легких пылевой этиологии с гиперлипидемией, гипербарическая оксигенация.

\section{E.G. Lyashenko, I.V. Mukhin}

SEI HPE «M. Gorky Donetsk National Medical University», Donetsk

\section{DYNAMICS OF SYSTEMIC INFLAMMATORY RESPONSE ACTIVITY UNDER THE INFLUENCE OF TREATMENT IN DONBASS MINING COAL MINES SUFFERING DUST COPD WITH DYSLIPIDEMIA}

The aim of the study was to analyze the effect of three modes of therapy on the indicators of the activity of the systemic inflammatory response in patients with chronic obstructive pulmonary disease of dusty etiology with dyslipidemia. The patients were found to have hyperactivity of the systemic inflammatory response. Hyperbaric oxygenation as a component of a complex short-term treatment and rehabilitation program can reliably reduce the activity of systemic inflammation more effectively than inhalation therapy with beta- 2 agonists and glucocorticoid hormones.

Key words: activity of the systemic inflammatory response, chronic obstructive pulmonary disease of dusty etiology with hyperlipidemia, hyperbaric oxygenation.

\section{ЛИТЕРАТУРА}

1. Глазачев О.С., Крыжановская С.Ю. Адаптационная медицина: стратегия психофизиологического приспособления человека к критически измененной окружающей среде. Вестник международной академии наук. 2019; 1: 48-55.

2. Бачинский О.Н., Бабкина В.И., Прибылов С.А. Системное воспаление при хронической обструктивной болезни легких профессиональной и непрофессиональной этиологии. Курский научно-практический вестник. 2011; 1: 26-30.

\section{REFERENCES}

1. Glazachev O.S., Kryzhanovskaya S.Yu. Adaptatsionnaya meditsina: strategiya psikhofiziologicheskogo prisposobleniya cheloveka k kriticheski izmenennoi okruzhayushchei srede. Vestnik mezhdunarodnoi akademii nauk. 2019; 1: 48-55 (in Russian).

2. Bachinskii O.N., Babkina V.I., Pribylov S.A. Sistemnoe vospalenie pri khronicheskoi obstruktivnoi bolezni legkikh professional'noi i neprofessional'noi etiologii. Kurskii nauchno-prakticheskii vestnik. 2011; 1: 26-30 (in Russian). 
3. Шпагина Л.А., Шпагин И.С., Котова О.С., Поспелова Т.И., Герасименко О.Н. Дифференцированная терапия различных фенотипов хронической обструктивной болезни легких. Пульмонология. 2016; 6: 681-693.

4. Николенко О.Ю., Ластков Д.О., Николенко В.Ю., Ляшенко Е. Г. Нарушения в иммунной системе у горнорабочих угольных шахт при пневмокониозе. Вестник гигиены и эпидемиологии. 2017; 2: 93-96.

5. Ніколенко О.Ю. Аутоімунні реакції при розвитку пневмоконіозу. Вісник гігієни та епідеміології. 2011; 1: $40-43$.

6. Чучалин А.Г., Шпагина Л.А., Васильева О.С. и др. Профессиональная хроническая обструктивная болезнь легких М.: ГЭОТАР-МЕДИА. 2015: 293-338.

7. Васильева О.С., Гусаков А.А., Гущина Е.Е., Кравченко Н.А. Хроническая обструктивная болезнь легких от воздействия производственных аэрозолей. Пульмонология. 2013; 3: 49-55.

8. Darby A.C., Waterhouse J.C., Stevens V., Billings C.G. et al. Chronic obstructive pulmonary disease among residents of an historically industrialised area. Thorax. 2012; 67 (10): 901-907.

9. Miller J., Edwards L.D., Agustí A. et al. Comorbidity, systemic inflammation and outcomes in the ECLIPSE cohort. Respir. Med. 2013; 107 (9): 1376-1384.

10. Alif S.M., Dharmage S.C., Bowatte G. et al. Occupational exposure and risk of chronic obstructive pulmonary disease: a systematic review and meta-analysis. Expert Rev. Respir. Med. 2016; 10 (8): 861-872.
3. Shpagina L.A., Shpagin I.S, Kotova O.S, Pospelova T.I. Gerasimenko O.N. Differentsirovannaya terapiya razlichnykh fenotipov khronicheskoi obstruktivnoi bolezni legkikh. Pul'monologiya. 2016; 6: 681-693 (in Russian).

4. Nikolenko O.Yu., Lastkov D.O., Nikolenko V.Yu., Lyashenko E. G. Narusheniya v immunnoi sisteme u gornorabochikh ugol'nykh shakht pri pnevmokonioze. Vestnik gigieny i epidemiologii. 2017; 2: 93-96 (in Russian).

5. Nikolenko O.Yu. Autoimunni reaktsiï pri rozvitku pnevmokoniozu. Visnik gigieni ta epidemiologiï. 2011; 1 : 40-43 (in Ukrainian).

6. Chuchalin A.G., Shpagina L.A., Vasil'eva O.S. i dr. Professional'naya khronicheskaya obstruktivnaya bolezn' legkikh M.: GEOTAR-MEDIA. 2015: 293-338 (in Russian).

7. Vasil'eva O.S., Gusakov A.A., Gushchina E.E., Kravchenko N.A. Khronicheskaya obstruktivnaya bolezn' legkikh ot vozdeistviya proizvodstvennykhaerozolei.Pul'monologiya. 2013; 3: 49-55 (in Russian).

8. Darby A.C., Waterhouse J.C., Stevens V., Billings C.G. et al. Chronic obstructive pulmonary disease among residents of an historically industrialised area. Thorax. 2012; 67 (10): 901-907.

9. Miller J., Edwards L.D., Agustí A. et al. Comorbidity, systemic inflammation and outcomes in the ECLIPSE cohort. Respir. Med. 2013; 107 (9): 1376-1384.

10. Alif S.M., Dharmage S.C., Bowatte G. et al. Occupational exposure and risk of chronic obstructive pulmonary disease: a systematic review and meta-analysis. Expert Rev. Respir. Med. 2016; 10 (8): 861-872. 